\title{
Changes in bone mineral density after total parathyroidectomy without autotransplantation in the end-stage renal disease patients with secondary hyperparathyroidism
}

\author{
Li Fang ${ }^{1,2 \dagger}$, Jining $\mathrm{Wu}^{2 \dagger}$, Jing Luo ${ }^{2}$, Ping Wen², Mingxia Xiong ${ }^{2}$, Jinlong $\mathrm{CaO}^{2}$, Xiaolan Chen ${ }^{1^{*}}$ and Junwei Yang ${ }^{2^{*}}$
}

\begin{abstract}
Background: The patients with secondary hyperparathyroidism (SHPT) usually had reduced bone mineral density, which might lead to a substantial increase in osteoporosis, fracture and mortality. Although surgical intervention is effective in reducing parathyroid hormone (PTH) levels in suitable candidates refractory to medical therapy, the effect of surgery on bone mass changes still requires further evaluation. Thus, the aim of this study was to evaluate the characteristics of BMD changes after total parathyroidectomy (PTX) without autotransplantation and its associated factors.

Methods: The records of 34 patients who underwent successful total PTX without autotransplantation with a preoperative and postoperative dual energy X-ray absorptiometry (DEXA) scan in our institution within 4 years of operative intervention were reviewed. Correlation and regression analysis were used to identify factors that independently predict BMD changes.
\end{abstract}

Results: At baseline, we found that the prevalence of osteoporosis seemed to be much higher in the load-bearing lumbar spine than in the hip, varying greatly even between different lumbar vertebrae. The bone loss in SHPT had its predilection site in the load-bearing cancellous bone. After curative total PTX without autotransplantation, BMD improved significantly in both lumbar spine and hip overall. The largest increase in BMD occurred at $L 4$ vertebrae with the lowest pre-operative BMD. At the most affected site L4, BMD improved in up to $94.1 \%$ of patients: $86.2 \%$ had significant improvement, 5.9\% moderate improvement, and 5.9\% declining bone mineral density. Correlation and regression analysis suggested that percentage changes in BMD were predicted negatively by the preoperative BMD and positively by the preoperative parathyroid mass but not intact PTH levels.

Conclusion: Total parathyroidectomy without autotransplantation could improve BMD of secondary hyperparathyroidism at L1-L4 and the hip. Furthermore, the large parathyroid glandular mass and the preoperative BMD predicted the BMD changes after surgery.

Keywords: Bone mineral density, Total parathyroidectomy without autotransplantation, Secondary hyperparathyroidism, Dual-energy X-ray absorptiometry, End-stage renal disease

\footnotetext{
* Correspondence: chenxl8448@sina.com; jwyang@njmu.edu.cn

${ }^{\dagger} \mathrm{Li}$ Fang and Jining Wu contributed equally to this work.

'Department of Nephrology, Affiliated Hospital of Nantong University, 20 Xisi

Road Nantong, Nantong, Jiangsu Province, China

${ }^{2}$ Department of Nephrology, Second Affiliated Hospital of Nanjing Medical

University, 262 Zhongshan North Road, Nanjing, Jiangsu Province, China
}

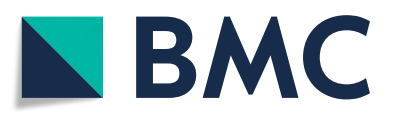

(c) The Author(s). 2018 Open Access This article is distributed under the terms of the Creative Commons Attribution 4.0 International License (http://creativecommons.org/licenses/by/4.0/), which permits unrestricted use, distribution, and

reproduction in any medium, provided you give appropriate credit to the original author(s) and the source, provide a link to the Creative Commons license, and indicate if changes were made. The Creative Commons Public Domain Dedication waiver (http://creativecommons.org/publicdomain/zero/1.0/) applies to the data made available in this article, unless otherwise stated. 


\section{Background}

Renal osteodystrophy is one of the major serious complications in patients with end stage renal disease (ESRD) receiving long-term hemodialysis [1]. In addition to the abnormalities of bone architecture that contribute to fracture risk $[2,3]$, renal osteodystrophy is also associated with the development of arterial calcification and cardiovascular disease [4-6]. Increasing risks of fractures, together with high cardiovascular morbidity and mortality rates, have recently drawn much attention to devise an effective treatment plan for renal osteodystrophy that hopefully will lead to an improved outcome.

Osteitis fibrosa cystica, which is the most commonly encountered bone abnormality in renal osteodystrophy, classically appeared as an increased bone turnover that was not only associated with reduced bone density but also with osteopenia and osteoporosis that predisposes to an increased risk of fracture [7]. Since secondary hyperparathyroidism (SHPT) characterized by persistent elevated parathyroid hormone $(\mathrm{PTH})$ and marked parathyroid hyperplasia is the leading cause of osteitis fibrosa cystica [8], the current recommended treatment for renal osteodystrophy is to manage secondary hyperparathyroidism, but not typical osteoporosis therapies. At the early stage, improvement of renal osteodystrophy would be an expected consequence of effectively suppressing PTH with phosphate binders, calcitriol analogs and calcimimetics. Whereas, at the late stage, the progressively reducing expression of calcium-sensing receptors and vitamin D receptors might result in resistance to medical therapy and surgical intervention might be gradually necessary to achieve adequate control of refractory secondary hyperparathyroidism [9-14]. However, it has also been reported that very low PTH levels and over-suppression of PTH were linked with adynamic bone disease, decreased bone mineral density (BMD) and a greater risk for fracture among long-term dialysis patients [15-17]. The impact of surgical intervention on bone health in secondary hyperparathyroidism remains uncertain, especially total parathyroidectomy without autotransplantation.

Thus, in this study, we sought to investigate the effect of total parathyroidectomy without autotransplantation on bone mineral density in the end-stage renal disease patients with refractory secondary hyperparathyroidism. Besides, we also examined the preoperative and postoperative clinical parameters to identify predictive factors related to the postoperative BMD changes.

\section{Methods}

\section{Participants}

We performed a retrospective analysis of 712 patients, who underwent total parathyroidectomy (PTX) without autotransplantation treatment for refractory secondary hyperparathyroidism in the second affiliated hospital of
Nanjing Medical University between January 2009 and December, 2015. Refractory SHPT was defined as following: 1) After regular drug treatment, serum intact PTH level $>500 \mathrm{pg} / \mathrm{mL}$ on two or more occasions; and/or 2) Patients with parathyroid nodular or diffuse hyperplasia identified by ultrasound imaging or radioisotope scan; 3) Patients with symptomatic secondary hyperparathyroidism, such as bone and joint pain, pathologic fractures, severe pruritus, restless legs syndrome and so on. All operations were carried out by the same surgical team. We identified 34 of these patients with a preoperative and postoperative DEXA scan in our institution within 4 years of operative intervention. Patients were excluded if either their pre- or postoperative DEXA scan was performed at an outside institution, if they were not cured from surgery (The relative reduction of 24 h-postoperative $\mathrm{iPTH}<90 \%$ ), or if they declined participation in research studies. The baseline characteristics of age, sex, duration of dialysis between the study participants and those excluded have no significant difference, as shown in Additional file 1: Table S1. However, the preoperative PTH levels were much higher in those excluded. In all patients, $4 \mathrm{~h}$ hemodialysis was performed three times a week using TORAY TR8000 machines. High flux polysulfone membrane (T-sulfone, Toray, Japan) were used. For dialysis of normal-size adults, the blood flow rate is usually set between 250 and $300 \mathrm{~mL} / \mathrm{min}$. Individual ultrafiltration rates were held constant, from $500 \mathrm{ml} / \mathrm{h}$ to $800 \mathrm{ml} / \mathrm{h}$ to achieve dry weight.

All procedures performed in the study involving human participants were in accordance with the ethical standards of the institutional and/or national research committee and with the 1964 Helsinki declaration and its later amendments or comparable ethical standards. Besides, this study was also approved by the ethics committee of Nanjing Medical University. There was no commercial sponsorship.

\section{Blood measurements}

Blood samples were obtained before the start of the hemodialysis session in a $12 \mathrm{~h}$-fasting state. Blood routine tests were performed using an LH-750 Hematology Analyzer (Beckman Coulter, Inc., Fullerton, CA). Laboratory assessment included blood urea nitrogen, serum creatinine, serum albumin, high-density lipoprotein cholesterol (HDLC), low-density lipoprotein cholesterol (LDLC), total cholesterol, triglyceride, magnesium, calcium, and phosphorus were performed using photometric method by Automatic Biochemical Analyzer (HITACHI 7080; Hitachi, Ltd., Tokyo, Japan). Serum iPTH levels were measured using a UniCel DxI800 Access Immunoassay System (Beckman Coulter, Inc., Fullerton, CA).

\section{BMD measurements}

Bone mineral density (BMD) were performed on Hologic Discovery duel-energy $\mathrm{x}$-ray absorptiometry scanner, 
using the manufacturer's recommended standard procedures for the postero-anterior lumbar spine at L1-L4, and the proximal femur at the femoral neck, trochanter, intertrochanteric region and total region. Standard deviation from the mean value of younger healthy ones was expressed as T-score, while the standard deviation from the mean value of age and gender-matched controls was expressed as Z-score. The results were evaluated according to World Health Organization (WHO) osteoporosis criteria: (a) normal, a BMD T-score greater than - 1 SD; (b) osteopenia, a T-score between -1 and $-2.5 \mathrm{SD}$; (c) osteoporosis, a T-score below $-2.5 \mathrm{SD}$.

\section{Statistical analyzes}

Statistical analysis was done with SPSS $15 \mathrm{~J}$ for Windows (SPSS, Chicago, IL, USA) to observe any significant differences. Data were presented as the mean (SD) for continuous variables with a normal distribution or median (interquartile range) for those with a skewed distribution. Student's paired t test was used to compare preoperative BMD values and biochemical values with those obtained after surgery. To investigate the possible variables influencing BMD changes, both univariate Spearman's correlation and stepwise multivariate linear regression analysis are used. We first used the univariate Spearman's correlation to analysis the relationship between BMD changes and the clinical parameters. When the variables are highly correlated, stepwise regression models in which the choice of predictive variables is carried out by an automatic procedure were then used to choose the independent variables. Differences were considered significant when $P$ value was less than 0.05 .

\section{Results}

Baseline demographics, clinical characteristics and biochemical profiles of our participants were presented in Table 1 . The study included 34 patients (14 women and 20 men) with a mean age of $49.7 \pm 8.44$ years (range, 31-65 years). The mean duration of dialysis before surgery was 84 (60-144) months. The serum intact PTH concentration (median and inter-quartile range) was $852.0(637.50-1058.78) \mathrm{pg} / \mathrm{ml}$. Besides, the derangements of calcium/phosphate homeostasis with serum phosphorus $2.23 \pm 0.409 \mathrm{mmol} / \mathrm{L}$ and serum calcium $2.56 \pm 0.211 \mathrm{mmol} / \mathrm{L}$ were also common seen.

To evaluate the effect of total parathyroidectomy without autotransplantation on BMD changes, we firstly assessed the characteristics of regional bone mineral density at lumbar spine and hip by dual energy X-ray absorptiometry before surgery. We found that there were significant differences in BMD values between various anatomic bone sites as shown in Additional file 2: Table S2. According to the WHO criteria based on T-scores, for lumbar spine, osteoporosis at L1 was revealed in $11.8 \%$ patients while at
Table 1 Baseline characteristics of the subjects with secondary hyperparathyroidism

\begin{tabular}{ll}
\hline & Patients $(n=34)$ \\
\hline Age, years & $49.7 \pm 8.44$ \\
Gender (male/female) & $20 / 14$ \\
Dialysis vintage, months & $84(60-144)$ \\
Kt $N$ & $1.4 \pm 0.19$ \\
Pre-PTX BMl & $23.6 \pm 4.91$ \\
Systolic blood pressure, mmHg & $134.4 \pm 16.34$ \\
Diastolic blood pressure, mmHg & $77.8 \pm 15.27$ \\
Hemoglobin, g/L & $114.6 \pm 18.83$ \\
C-reactive protein, mg/L & $14.6 \pm 29.78$ \\
Serum creatinine, umol/L & $952.2 \pm 240.79$ \\
Albumin, g/L & $44.8 \pm 3.87$ \\
Alkaline phosphatase, U/L & $165.9 \pm 115.81$ \\
Calcium, mg/dl & $2.56 \pm 0.211$ \\
Phosphorus, mg/dl & $2.23 \pm 0.409$ \\
Pre-PTX intact PTH, pg/ml & $852.0(637.5-1058.78)$ \\
Post-PTX intact PTH, pg/ml & $1.2(0.8-2.5)$ \\
\hline Continuous da are presen
\end{tabular}

Continuous data are presented as mean \pm SD when normally distributed and as median (interquartile range) when skewed

L4 was in $32.4 \%$ patients; for the hip, the femoral neck yielded the highest frequency of diagnosis of osteoporosis (23.5\%) and next came the intertrochanter (17.6\%). These data indicated that the bone involvement in severe secondary hyperparathyroidism had its predilection site and the assessment of changes should be taken separately for different anatomical sites.

Overall, as presented in Additional file 2: Table S2, bone mineral density had improved significantly after total parathyroidectomy. The increases in BMD and T-scores were much greater for the lumbar spine than for the hip. When we analyzed the characterization of improvement in details, in the lumbar area, we found that the increase in bone mineral content was significant while the change in bone area was not obvious (as shown in Fig. 1a-e); while in the hip, although not statistically significant, we found the increase in bone mineral content was always accompanied by the reduction of bone area (as shown in Fig. 2a-d). According to the previous research [18], we likewise defined significant improvement if the patients' BMD increased $>5 \%$ during the postoperative follow-up period and moderate improvement if they had a BMD increase of $0.1-5 \%$. As illustrated in Figs. If and 2e, we found that the largest increases in BMD occurred at sites with the lowest pre-operative BMD. At the most frequently affected sites in the lumbar region L4, 86.2\% of patients had significant improvement $(>5 \%)$ in BMD, $5.9 \%$ had moderate improvement $(0.1-5 \%)$ and $5.9 \%$ had declining bone mineral density. Similarly, in the hip region, $76.5 \%$ of 


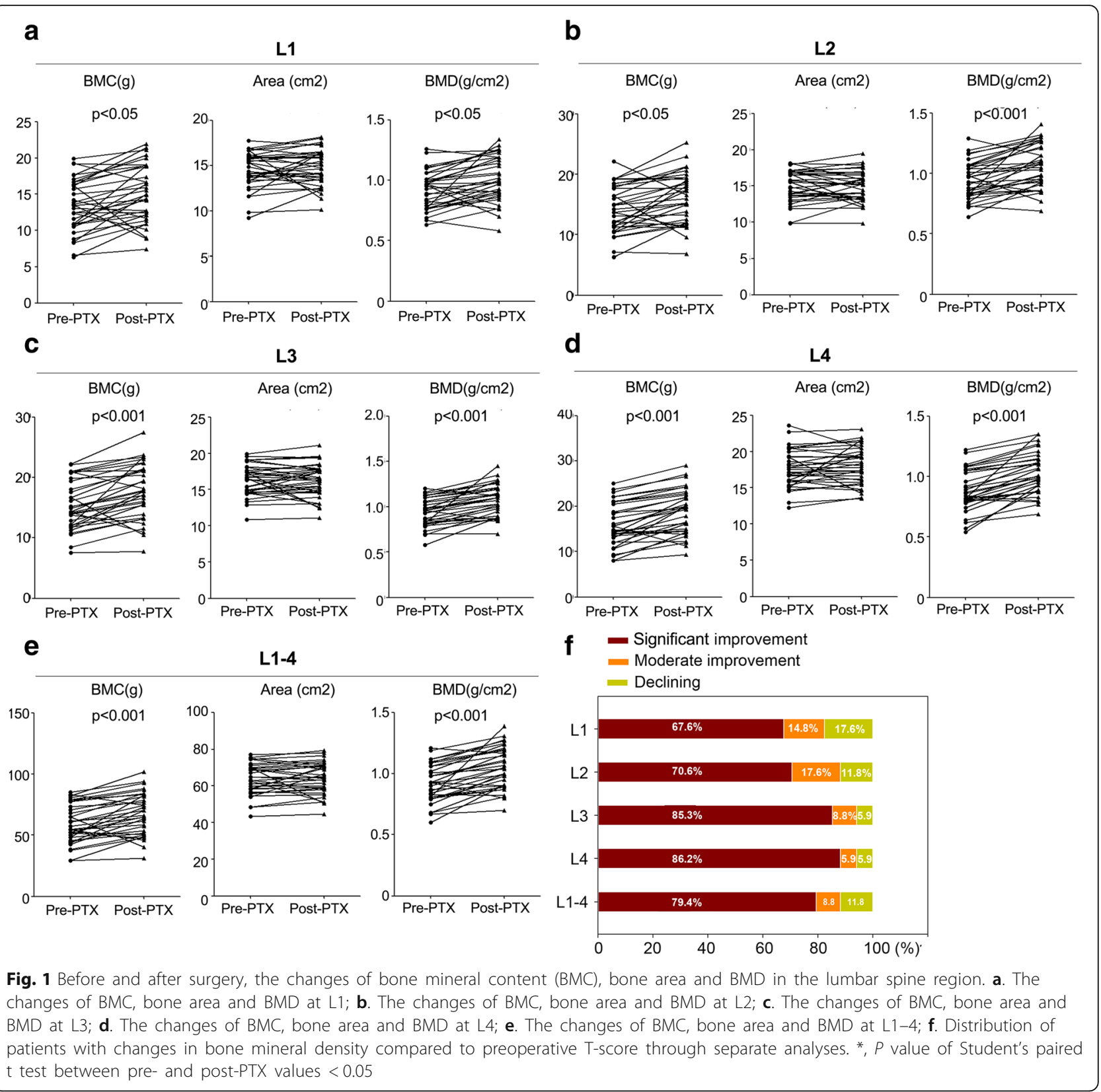

patients had significant improvement at the femoral neck where yielded the highest frequency of diagnosis of osteoporosis.

On correlation analysis (as shown in Table 2), we found that the percentage change in L1-L3 vertebra BMD but not hip were positively correlated with preoperative intact $\mathrm{PTH}$, postoperative changes of PTH in $24 \mathrm{~h}$ and mass of preoperative parathyroid glands. Yet no correlations were observed between BMD changing rates with ages, gender, dialysis vintage, weight and height and time after surgery in both the lumbar spine and hip. As illustrated in Additional file 3: Figure S1, when we divided the patients into three groups according to the postoperative durations, we found that the postoperative durations did not affect the changes in BMD after surgery. Instead, there was a trend of correlation between percentage change in BMD and the preoperative bone lesions. In the multiple linear regression analysis (Table 3), we unexpectedly found that the BMD changes in most measured regions were affected by the mass of resected parathyroid glands. Besides, preoperative $\mathrm{BMD}$, preoperative height, preoperative weight also participated in explaining the changes of BMD.

\section{Discussion}

Secondary hyperparathyroidism, which was ubiquitous in patients on maintenance hemodialysis, has now been 


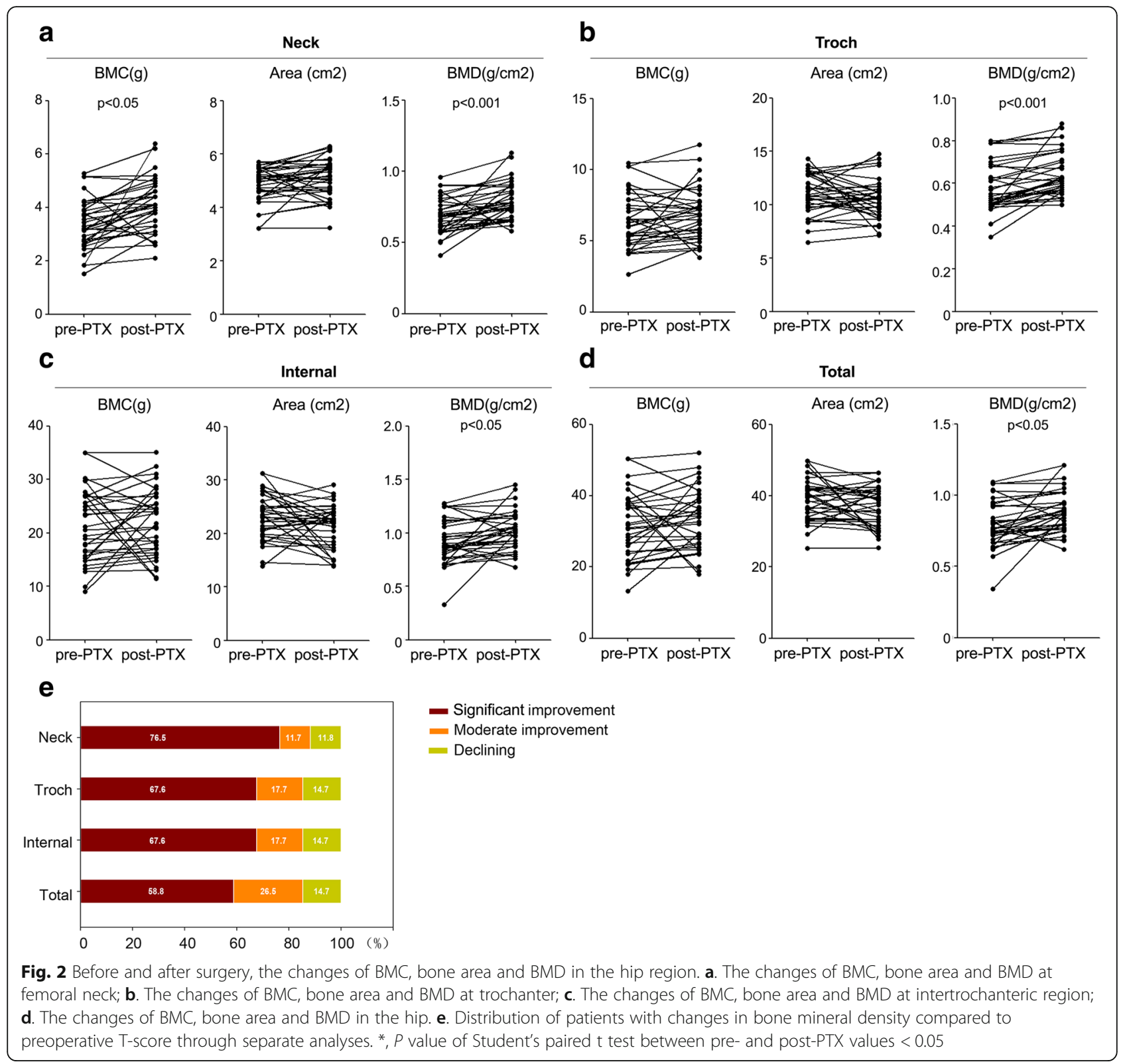

recognized as the predominant cause of renal osteodystrophy. In the early stage, by targeting secondary hyperparathyroidism, renal osteodystrophy could easily be managed with medical treatment. However, in the late stage, despite considerable advances in medical therapies, surgical treatment which has already proven to be much more cost effective in the long term remains necessary for treating refractory disease at times [13]. Yet surgical consensus on the optimal procedure has not been reached, total parathyroidectomy without autotransplantation is gradually accepted and recommended because of the higher cure rate and the lower recurrence rate [14, 19-22]. Concerning the possible adverse impact on bone health in absence of PTH, our present study herein was mainly focused on the bone mineral status in secondary hyperparathyroidism and the effect of total parathyroidectomy without autotransplantation on bone density changes.

In concordance with previous studies, our data demonstrated that most of the patients with refractory SHPT displayed a marked reduction of bone density. And the BMD reduction was preferentially seen at cancellous (e.g. lumbar spine) versus cortical bone sites, although protracted elevation of serum parathyroid hormone (PTH) was held to be associated with cortical, but not cancellous, bone loss [23-25]. After successful total parathyroidectomy without autotransplantation, further bone loss could be halted and BMD subsequently 
Table 2 Univariate Spearman's correlation coefficients for the relationships between clinical parameters and percentage change in $\mathrm{BMD}$ at the lumbar spine and hip after total parathyroidectomy (PTX) without autotransplantation

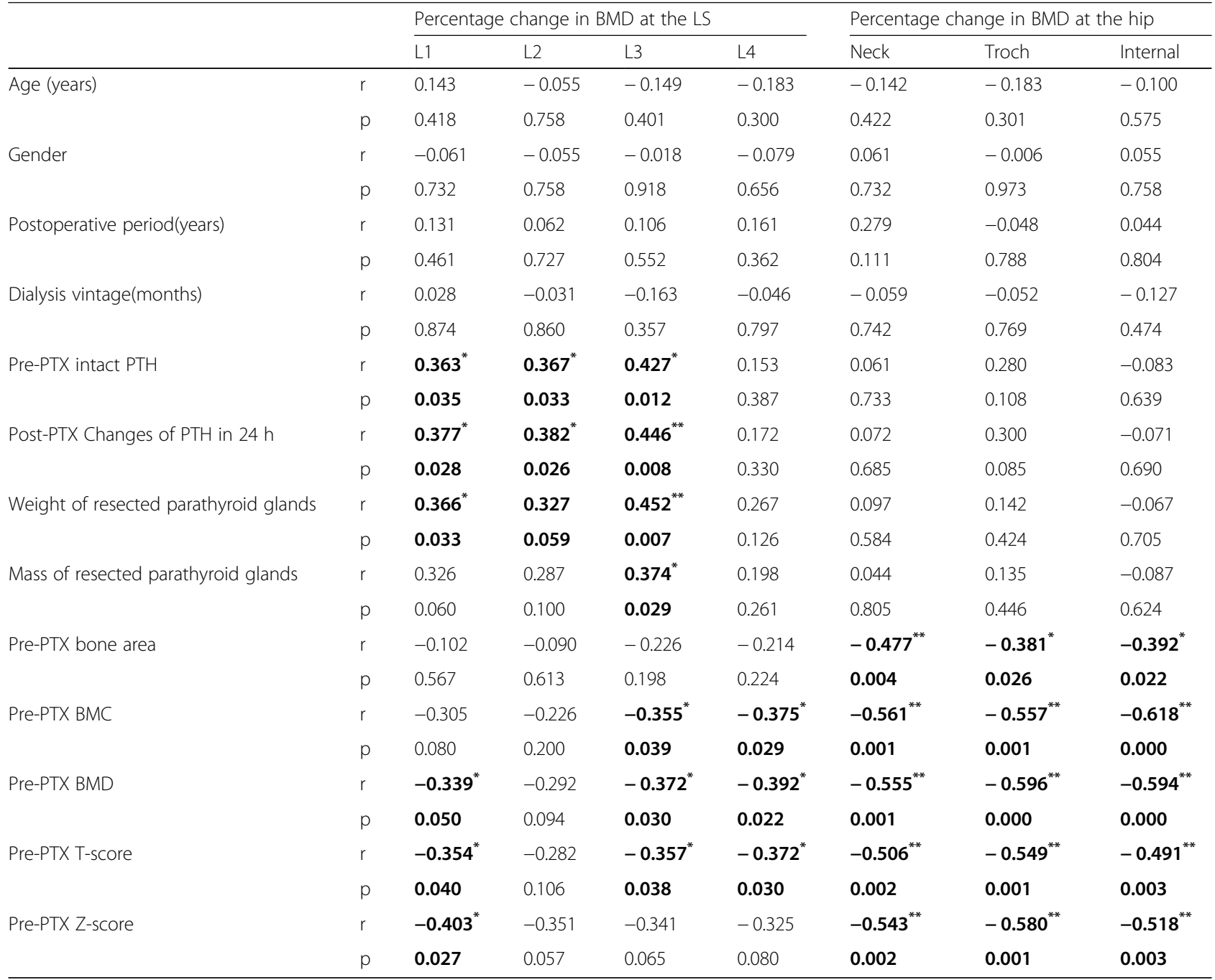

* Significant at $p<0.05$ level; ** Significant at $p<0.01$ level. $p$ values in bold indicate significance levels

increased at nearly all skeletal sites. The lumbar spine showed a greater increase in BMD than the hip and the greatest increase in BMD was observed in the weight-bearing L4. This indicated that the sites with lowest BMD might benefit most from surgical cure. However, unlike the increase observed by Mohamed et al. in their parathyroidectomized patients [26], we observed the most marked regain in areas rich in cancellous bone whereas they found the largest increase at sites with predominantly cortical bone. Although the mechanisms underlying this discrepancy is not evident, but in both studies the largest increase in bone density occurred at the sites with the lowest preoperative BMD.

In addition to preoperative bone abnormalities, the effect of curative parathyroid resection on BMD changes was also affected by the preoperative hyperparathyroidism status, but not by age, gender, dialysis vintage and postoperative period. In the previous studies, Mohamed et al. have demonstrated that the parathyroidectomy resulted in an increased bone mass during the first 6-12 months after surgery [26]; Aiji Yajima et al. have further demonstrated that the osteoblast number increased 1 week after surgery compared with before parathyroidectomy, and the production of lamellar osteoid was detected [24]. These studies suggested that the postoperative BMD might increase mainly within the first year. That might be the reason why we found that the postoperative durations did not affect the changes in BMD after surgery. Most interestingly, with Spearman's correlation, we found that percentage changes in BMD were correlated with both preoperative intact PTH levels and preoperative parathyroid masses; whereas, with linear regression which was determined as the best way to predict effect from cause, percentage changes in BMD were predicted only by 
Table 3 Stepwise multivariate linear regression models of changes in BMD for the lumbar spine and hip

\begin{tabular}{|c|c|c|c|}
\hline & $\beta$ & SE & $p$ value \\
\hline \multicolumn{4}{|l|}{ Lumbar Spine } \\
\hline \multicolumn{4}{|l|}{ Percentage change in BMD at L1 } \\
\hline Mass of resected parathyroid glands & 0.021 & 0.003 & 0.000 \\
\hline Pre-PTX height & 0.005 & 0.002 & 0.033 \\
\hline \multicolumn{4}{|l|}{ R2 for the model $=0.648$} \\
\hline \multicolumn{4}{|l|}{ Percentage change in BMD at $\mathrm{L} 2$} \\
\hline Mass of resected parathyroid glands & 0.019 & 0.003 & 0.000 \\
\hline Pre-PTX BMD & -0.420 & 0.153 & 0.012 \\
\hline Pre-PTX height & 0.005 & 0.002 & 0.030 \\
\hline \multicolumn{4}{|l|}{ R2 for the model $=0.692$} \\
\hline \multicolumn{4}{|l|}{ Percentage change in BMD at L3 } \\
\hline Mass of resected parathyroid glands & 0.019 & 0.003 & 0.000 \\
\hline Pre-PTX BMD & -0.389 & 0.127 & 0.005 \\
\hline \multicolumn{4}{|l|}{ R2 for the model $=0.746$} \\
\hline \multicolumn{4}{|l|}{ Percentage change in BMD at $L 4$} \\
\hline Mass of resected parathyroid glands & 0.015 & 0.003 & 0.000 \\
\hline Pre-PTX BMD & -0.498 & 0.137 & 0.001 \\
\hline Pre-PTX Albumin & 0.011 & 0.005 & 0.034 \\
\hline \multicolumn{4}{|l|}{ R2 for the model $=0.654$} \\
\hline \multicolumn{4}{|l|}{ Hip } \\
\hline \multicolumn{4}{|l|}{ Percentage change in BMD at femoral neck } \\
\hline Pre-PTX BMC & -0.166 & 0.039 & 0.000 \\
\hline Mass of resected parathyroid glands & 0.017 & 0.005 & 0.003 \\
\hline \multicolumn{4}{|l|}{ R2 for the model $=0.618$} \\
\hline \multicolumn{4}{|l|}{ Percentage change in BMD at trochanter } \\
\hline Mass of resected parathyroid glands & 0.018 & 0.003 & 0.000 \\
\hline Pre-PTX BMC & -0.053 & 0.010 & 0.000 \\
\hline \multicolumn{4}{|l|}{ R2 for the model $=0.765$} \\
\hline \multicolumn{4}{|c|}{ Percentage change in $\mathrm{BMD}$ at intertrochanter } \\
\hline Pre-PTX weight & 0.010 & 0.002 & 0.000 \\
\hline Pre-PTX BMD & -0.658 & 0.125 & 0.000 \\
\hline R2 for the model $=0.769$ & & & \\
\hline
\end{tabular}

*Significant at $p<0.05$ level; ** Significant at $p<0.001$ level

preoperative parathyroid masses but not intact $\mathrm{PTH}$ levels. As we pointed in the previous study [9], PTH levels might be influenced by multiple pharmaceutical drugs in short term, while the size of parathyroid gland might be a much more accurate marker reflecting the long-term hyperparathyroidism status. Base on this point, our data suggested that the bone mineral status in secondary hyperparathyroidism and changes after surgical cure were strongly associated with chronic hyperparathyroidism status. However, since our study was based on the retrospective and uncontrolled data, there are many limitations of our study, such as selection bias, lack of close follow up, lack of data on bone biopsy, bone metabolic markers, and fracture risk. In the future, well designed randomized controlled trials are still needed to come to a solid conclusion.

\section{Conclusion}

In summary, despite the limitation of a small sample size, the lack of matched control group and the lack of bone histomorphometric data, our present study, in combination with previous report [27, 28], still provided some useful bone informations that amelioration of biochemical consequences of secondary hyperparathyroidism by total parathyroidectomy without autotransplantation might have a positive effect in BMD.

\section{Additional files}

Additional file 1: Table S1. The baseline characteristics of the study participants and those excluded. (DOC $27 \mathrm{~kb}$ )

Additional file 2: Table S2. Results of dual X-ray absorbtiometry (DXA) before and after total parathyroidectomy (PTX). (DOC 51 kb)

Additional file 3: Figure S1. BMD changes after surgery in the participants with different postoperative durations. A-E: BMD changes in the lumbar spine region; G-I: BMD changes in the hip region. (TIF $37610 \mathrm{~kb}$ )

\section{Abbreviations}

BMC: Bone mineral content; BMD: Bone mineral density; DEXA: Dual energy X-ray absorptiometry; ESRD: End-stage renal disease; HDLC: High-density lipoprotein cholesterol; i-PTH: Intact-parathyroid hormone; LDLC: Low-density lipoprotein cholesterol; PTX: Parathyroidectomy; SHPT: Secondary hyperparathyroidism; WHO: World Health Organization

\section{Acknowledgements}

We thank Prof. Dawei Hou for his contributions during the project implementation process.

\section{Funding}

This work was supported by National Science Foundation of China Grants (31400980) and Natural Science Foundation of Jiangsu Province (BK2014014) to Li Fang.

\section{Availability of data and materials}

The datasets created during and/or analyzed during the current study available from the corresponding author on reasonable request.

\section{Authors' contributions}

Study design: LF, JY; Study conduct: JL, PW, MX, JC; Data collection: LF, JW, $X C$; Data analysis: LF, JY; Data Interpretation: LF, XC, JY; Drafts manuscript: LF, JW, JY; Revision: LF, JW, JY. All the authors have read and approved the manuscript for submission.

\section{Ethics approval and consent to participate}

Since this study was a retrospective one using clinical data, and it did not involve further invasive intervention, treatment, or costs to patients, the study received a consent exemption and it was approved by the ethics committee of Nanjing Medical University. The patient's record was deidentified and analyzed anonymously. This study was performed in accordance with the ethical standards of the institutional and/or national research committee and with the 1964 Helsinki declaration and its later amendments or comparable ethical standards. There was no commercial sponsorship.

\section{Competing interests}

The authors declare that they have no competing interests. 


\section{Publisher's Note}

Springer Nature remains neutral with regard to jurisdictional claims in published maps and institutional affiliations.

Received: 17 August 2017 Accepted: 28 May 2018

Published online: 15 June 2018

\section{References}

1. Trombetti A, Stoermann C, Chevalley T, Van Rietbergen B, Herrmann FR, Martin PY, Rizzoli R. Alterations of bone microstructure and strength in endstage renal failure. Osteoporos Int. 2013;24(5):1721-32.

2. Bucur RC, Panjwani DD, Turner L, Rader T, West $S L$, Jamal SA. Low bone mineral density and fractures in stages 3-5 CKD: an updated systematic review and meta-analysis. Osteoporos Int. 2015;26(2):449-58.

3. West SL, Lok CE, Langsetmo L, Cheung AM, Szabo E, Pearce D, Fusaro M, Wald R, Weinstein J, Jamal SA. Bone mineral density predicts fractures in chronic kidney disease. J Bone Miner Res. 2015;30(5):913-9.

4. Cejka D, Weber M, Diarra D, Reiter T, Kainberger F, Haas M. Inverse association between bone microarchitecture assessed by HR-pQCT and coronary artery calcification in patients with end-stage renal disease. Bone. 2014;64:33-8.

5. Disthabanchong S, Jongjirasiri S, Adirekkiat S, Sumethkul V, Ingsathit A, Domrongkitchaiporn S, Phakdeekitcharoen B, Kantachuvesiri S, Kitiyakara C. Low hip bone mineral density predicts mortality in maintenance hemodialysis patients: a five-year follow-up study. Blood Purif. 2014; 37(1):33-8.

6. Block GA, Klassen PS, Lazarus JM, Ofsthun N, Lowrie EG, Chertow GM. Mineral metabolism, mortality, and morbidity in maintenance hemodialysis. J Am Soc Nephrol. 2004;15(8):2208-18.

7. Fukagawa M, Kazama JJ, Kurokawa K. Renal osteodystrophy and secondary hyperparathyroidism. Nephrol Dial Transplant. 2002;17(Suppl 10):2-5.

8. O'Flaherty D, Sankaralingam A, Scully P, Manghat P, Goldsmith D, Hampson G. The relationship between intact PTH and biointact PTH (1-84) with bone and mineral metabolism in pre-dialysis chronic kidney disease (CKD). Clin Biochem. 2013:46(15):1405-9.

9. Fang L, Tang B, Hou D, Meng M, Xiong M, Yang J. Relationship between parathyroid mass and parathyroid hormone level in hemodialysis patients with secondary hyperparathyroidism. BMC Nephrol. 2015;16:82.

10. He Q, Zhuang D, Zheng L, Fan Z, Zhou P, Zhu J, Duan S, Li Y, Ge Y, Lv Z, et al. Total parathyroidectomy with trace amounts of parathyroid tissue autotransplantation as the treatment of choice for secondary hyperparathyroidism: a single-center experience. BMC Surg. 2014;14:26.

11. Polistena A, Sanguinetti A, Lucchini R, Galasse S, Avenia S, Monacelli M, Johnson LB, Jeppsson B, Avenia N. Surgical treatment of secondary hyperparathyroidism in elderly patients: an institutional experience. Aging Clin Exp Res. 2017;29(Suppl 1):23-8.

12. Lorenz K, Bartsch DK, Sancho JJ, Guigard S, Triponez F. Surgical management of secondary hyperparathyroidism in chronic kidney diseasea consensus report of the European Society of Endocrine Surgeons. Langenbeck's Arch Surg. 2015;400(8):907-27.

13. Ghani A, Baxter P. Surgical parathyroidectomy versus cinacalcet therapy: in the management of secondary hyperparathyroidism. Otolaryngol Head Neck Surg. 2012;146(2):220-5.

14. Conzo G, Perna AF, Sinisi AA, Palazzo A, Stanzione F, Della Pietra C, Livrea A Total parathyroidectomy without autotransplantation in the surgical treatment of secondary hyperparathyroidism of chronic kidney disease. J Endocrinol Investig. 2012;35(1):8-13.

15. Coco M, Rush $\mathrm{H}$. Increased incidence of hip fractures in dialysis patients with low serum parathyroid hormone. Am J Kidney Dis. 2000;36(6):1115-21.

16. Fishbane S, Hazzan AD, Jhaveri KD, Ma L, Lacson E Jr. Bone parameters and risk of hip and femur fractures in patients on hemodialysis. Clin J Am Soc Nephrol. 2016;11(6):1063-72.

17. Pelletier S, Vilayphiou N, Boutroy S, Bacchetta J, Sornay-Rendu E, Szulc P, Arkouche W, Guebre-Egziabher F, Fouque D, Chapurlat R. Bone microarchitecture is more severely affected in patients on hemodialysis than in those receiving peritoneal dialysis. Kidney Int. 2012;82(5):581-8.

18. Dy BM, Grant CS, Wermers RA, Kearns AE, Huebner M, Harmsen WS, Thompson GB, Farley DR, Richards ML. Changes in bone mineral density after surgical intervention for primary hyperparathyroidism. Surgery. 2012; 152(6):1051-8
19. Ockert S, Willeke F, Richter A, Jonescheit J, Schnuelle P, Van Der Woude F, Post S. Total parathyroidectomy without autotransplantation as a standard procedure in the treatment of secondary hyperparathyroidism. Langenbeck's Arch Surg. 2002;387(5-6):204-9.

20. Puccini M, Carpi A, Cupisti A, Caprioli R, lacconi P, Barsotti M, Buccianti P, Mechanick J, Nicolini A, Miccoli P. Total parathyroidectomy without autotransplantation for the treatment of secondary hyperparathyroidism associated with chronic kidney disease: clinical and laboratory long-term follow-up. Biomed Pharmacother. 2010;64(5):359-62.

21. Coulston JE, Egan R, Willis E, Morgan JD. Total parathyroidectomy without autotransplantation for renal hyperparathyroidism. Br J Surg. 2010;97(11):1674-9

22. Shih ML, Duh OY, Hsieh CB, Lin SH, Wu HS, Chu PL, Chen TY, Yu JC. Total parathyroidectomy without autotransplantation for secondary hyperparathyroidism. World J Surg. 2009:33(2):248-54.

23. Bandeira F, Cassibba S. Hyperparathyroidism and bone health. Curr Rheumatol Rep. 2015:17(7):48.

24. Yajima $A$, Inaba $M$, Tominaga $Y$, Ito A. Minimodeling reduces the rate of cortical bone loss in patients with secondary hyperparathyroidism. Am J Kidney Dis. 2007:49(3):440-51.

25. Nickolas TL, Stein EM, Dworakowski E, Nishiyama KK, Komandah-Kosseh M, Zhang CA, McMahon DJ, Liu XS, Boutroy S, Cremers S, et al. Rapid cortical bone loss in patients with chronic kidney disease. J Bone Miner Res. 2013; 28(8):1811-20.

26. Abdelhadi M, Nordenstrom J. Bone mineral recovery after parathyroidectomy in patients with primary and renal hyperparathyroidism. J Clin Endocrinol Metab. 1998;83(11):3845-51.

27. Rudser KD, de Boer $\mathrm{IH}$, Dooley A, Young B, Kestenbaum B. Fracture risk after parathyroidectomy among chronic hemodialysis patients. J Am Soc Nephrol. 2007;18(8):2401-7.

28. Isaksson E, Ivarsson K, Akaberi S, Muth A, Sterner G, Karl-Goran P, Clyne N, Almquist $M$. The effect of Parathyroidectomy on risk of hip fracture in secondary hyperparathyroidism. World J Surg. 2017:41(9):2304-11.

\section{Ready to submit your research? Choose BMC and benefit from:}

- fast, convenient online submission

- thorough peer review by experienced researchers in your field

- rapid publication on acceptance

- support for research data, including large and complex data types

- gold Open Access which fosters wider collaboration and increased citations

- maximum visibility for your research: over $100 \mathrm{M}$ website views per year

At BMC, research is always in progress.

Learn more biomedcentral.com/submissions 